\title{
BMJ Open A cross-sectional study on person- centred communication in the care of older people: the COMHOME study protocol
}

\author{
Linda Hafskjold, ${ }^{1}$ Annelie J Sundler, ${ }^{2,3}$ Inger K Holmström, ${ }^{2,4}$ Vibeke Sundling, ${ }^{1}$ \\ Sandra van Dulmen, ${ }^{1,5,6}$ Hilde Eide $^{1}$
}

To cite: Hafskjold L Sundler AJ, Holmström IK, et al. A cross-sectional study on person-centred communication in the care of older people: the COMHOME study protocol. BMJ Open 2015;5:e007864. doi:10.1136/bmjopen-2015007864

- Prepublication history for this paper is available online To view these files please visit the journal online (http://dx.doi.org/10.1136/ bmjopen-2015-007864).

Received 27 February 2015 Revised 10 March 2015 Accepted 12 March 2015

CrossMark

For numbered affiliations see end of article.

Correspondence to Professor Hilde Eide; hilde.eide@hbv.no

\section{ABSTRACT \\ Introduction: This paper presents an international cross-sectional study on person-centred communication with older people receiving healthcare (COMHOME). Person-centred care relies on effective communication, but few studies have explored this with a specific focus on older people. The main aim of the COMHOME study is to generate knowledge on person-centred communication with older people (>65 years) in home healthcare services, radiographic and optometric practice.}

Methods and analysis: This study will explore the communication between care providers and older persons in home care services. Home healthcare visits will be audiorecorded $(n=500)$ in Norway, the Netherlands and Sweden. Analyses will be performed with the Verona Coding Definitions for Emotional Sequences (VR-CoDES), the Roter Interaction Analysis System (RIAS) and qualitative methods. The content of the communication, communicative challenging situations as well as empathy, power distance, decision-making, preservation of dignity and respect will be explored. In Norway, an additional 100 encounters, 50 in optometric practice (video recorded) and 50 in radiographic practice (audiorecorded), will be analysed. Furthermore, healthcare providers' self-reported communication skills, empathy, mindfulness and emotional intelligence in relation to observed person-centred communication skills will be assessed using wellestablished standardised instruments.

Ethics and dissemination: Depending on national legislation, approval of either the central ethical committees (eg, nation or university), the national data protection officials or the local ethical committees (eg, units of home healthcare) was obtained. Study findings will be disseminated widely through peer-reviewed publications and conference presentations. The research findings will add knowledge to improve services provided to this vulnerable group of patients. Additionally, the findings will underpin a training programme for healthcare students and care providers focusing on communication with older people.

\section{Strengths and limitations of this study}

- The study will explore person-centred communication with older people (>65 years)

- The settings are home healthcare, radiographic and optometric practice.

- Nursing staffs' communication will be compared in three European countries.

- Key issues in emotional as well as task-focused communication will be highlighted.

- The findings will be used in education of healthcare students and providers.

\section{INTRODUCTION}

Communication is a basic competence and a cornerstone in healthcare encounters. ${ }^{1-3}$ Through verbal and non-verbal communication, patients express their symptoms and concerns as well as their expectations, hopes and fears for treatment and care. ${ }^{2}{ }^{4}$ Healthcare providers explore the patient's situation by listening and asking questions; they discuss care and treatment alternatives with the patient and they provide the patient with information. These aspects of communication are essential for empowering patients, and improving their health and quality of life. Insufficient communication, caused by the healthcare provider's inability to be attentive and truly meet the patient's queries, may result in unnecessary suffering in older people. $^{5}$ Despite the importance of highquality communication, ${ }^{6}$ few studies have systematically examined communication with older people in the setting of healthcare services frequently used by this group of people, that is, home healthcare, radiography and optometry.

Health policies aim at active ageing and for people living at home as long as possible. ${ }^{6-10}$ However, the rapid increase of 
age-related diseases ${ }^{11} 12$ increases the complexity of procedures and the need for individualised care delivered by all healthcare professionals to older people. There is growing evidence that person-centred care has a positive impact on different patient outcomes such as patient empowerment as a way of strengthening participation and autonomy, ${ }^{13}$ patient satisfaction, ${ }^{14}$ health ${ }^{15}$ and length of hospital stay. ${ }^{16}$ Person-centred care is especially important for older people in order to optimise functional health, ensure independence and provide highquality care. $^{17} 18$

Communicative abilities of older people may deteriorate because of impaired hearing and vision loss, as well as cognitive impairment. ${ }^{19} 20$ Care providers' communication behaviours encouraging patient choice and participation in decision-making can make a significant impact on older people's sense of control of their own life. ${ }^{21}$ Different healthcare contexts may influence the patient-provider communication as shown in home healthcare, ${ }^{22-25}$ clinical settings in hospital, ${ }^{26}{ }^{27}$ in technical settings such as in a radiology department, ${ }^{28} 29$ and in a commercial setting where the patient is also a customer, such as in optometric practice. A study including home healthcare, optometry and radiography may provide important insight into the influence of contextual factors on patient-provider communication and into factors that are transferable to a wider context.

Despite the importance of communication in healthcare, ${ }^{30}{ }^{31}$ few studies have systematically examined communication with older people in need of home healthcare services. ${ }^{23} 32$ To the best of our knowledge, no studies have examined communication with older people using optometry; very few examined communication, including radiographers' communication, when performing advanced imaging procedures ${ }^{33-35}$ and none studied communication targeting the older patient group. More than $20 \%$ of the patients encountered in optometric practice are 65 years or older. ${ }^{36}$ Further, a rapid increase in the use of advanced, diagnostic imaging procedures such as CT scan is occurring in all western countries ${ }^{37}$ and a dramatic increase of such tests is documented as being currently used when examining older people. ${ }^{38}$ To increase the participation of older people, and to improve their care and the healthcare services in general, more knowledge will facilitate training of person-centred communication in home healthcare as well as commonly used healthcare services such as radiography and optometry.

In the COMHOME study, we will compare personcentred communication with older people in home healthcare practices in three European countries, Norway, Sweden and the Netherlands, as well as explore communication practice in optometry and radiography in Norway and develop a training programme for healthcare workers and students to enhance communication with older people.
Theoretical framework and concepts

\section{Person-centred care and person-centred communication}

During the past two decades, person-centred care and related concepts, such as patient involvement and patient participation, are receiving more attention. The concept of person-centred care used in research and policy documents are linked to high-quality care. ${ }^{9} \quad 10 \quad 39-41$ However, there is no consensus on the definition of person-centred care and there is a need for theory development. ${ }^{13}$

A reoccurring theme in definitions of person centeredness is the ethical idea that patients should be 'treated as persons', ${ }^{42}$ that is, the patient is viewed in the context of their own social world, respected and involved in their own care. ${ }^{43}$

The theoretical point of departure for this study is the theory and philosophy of Carl Rogers, ${ }^{44}$ and his personcentred approach based on principles and values of acceptance, caring, empathy and sensitivity in human interactions. Essential to this and other theories on person-centred care is the providers' ability to communicate and interact with the patient in a person-centred way. ${ }^{3} 4245$ Person-centred communication aims specifically at ensuring the healthcare provider's attention to the whole person and includes: sharing information and decisions, providing compassionate and empowering care, and being sensitive to patient needs. ${ }^{46}$ Personcentred communication has also been identified as a prerequisite to elicit person-centred care. ${ }^{45}$ In this study, we define the concept of person-centred communication as a set of skills of the health provider demonstrated through verbal, paraverbal and non-verbal communication that facilitates person-centred care. Traits of the healthcare provider, such as empathy, mindfulness and emotional intelligence, probably influence both the care delivered and communication behaviour, and therefore these traits need to be taken into account.

\section{Empathy and empathic accuracy}

Empathy is regarded as a basic competence in all helping relationships. ${ }^{3} 47$ Intermediate outcomes of empathic communication, such as trust, mutual understanding, medication adherence, social support and selfefficacy, are factors that are shown to correlate with positive health outcomes and should, therefore, be promoted in encounters with patients. ${ }^{48}$ However, studies have shown that empathic communication is not sufficiently applied in clinical practice. ${ }^{49} 50$

\section{Mindfulness and emotional intelligence}

In this study we specifically address two concepts closely related to person-centred communication and care: mindfulness and emotional intelligence. We apply the concept of mindfulness as a psychological concept defined as the process of drawing novel distinctions by being present here and now. ${ }^{51}$ The degree of mindfulness may affect the healthcare provider's ability to 
observe what is going on and to act according to what is being noticed. ${ }^{52}$ Furthermore, healthcare providers who score high on mindfulness are shown to be more person centred when they communicate, and they have more satisfied patients. ${ }^{53}{ }^{54}$ Emotional intelligence is defined as the ability to recognise, express and regulate feelings and emotions in one's self and in others, and to utilise feelings and emotions to motivate, plan and develop actions. Emotional intelligence is closely related to interpersonal skills and communication skills which are important in clinical work and professional practice. ${ }^{55} 56$ To date, we do not know how emotional intelligence corresponds with communication practice in home healthcare, optometric or radiographic practice.

\section{Measurement of person centredness}

We define person centredness by observation of communication patterns using established coding schemes. The Verona Coding Definintion for Emotional Sequences (VR-CoDES) ${ }^{57}$ identifies moments in the interaction regarding patient's emotional expression that need exploration or confirmation in the form of empathy and understanding from the provider. The Roter Interaction Analysis System (RIAS) codes all communication and distinguishes task-focused and socioemotional-focused behaviour. ${ }^{58}$ To date, we have found no measurement instrument, neither a rating scale nor a questionnaire, that is suitable for measuring person-centred communication and person-centred care in the home health setting. Most instruments developed focus on older people with cognitive impairments in nursing homes $^{59} 60$ or the consultation in a hospital setting. ${ }^{61}$ There is a need to evaluate the quality of the interaction with and care given to older people, and a need for the development of a rating scale for person-centred care and communication with older people.

\section{Aims of the study}

This article describes the research protocol of the COMHOME study. The COMHOME project aims at providing knowledge on current practice in healthcare for community-dwelling older people. Findings will underpin a research-based online training platform for person-centred communication with older people (age $\geq 65$ years), targeting healthcare providers and healthcare students of different professions.

To achieve the aims of this study, we are going to explore how and to what extent healthcare providers practice person-centred communication in three different settings: home healthcare, optometric practice and during CT examinations. We will compare communication with older people and identify which factors facilitate or hinder person-centred communication such as time constraints, characteristics of the patient, the tasks and the provider. Furthermore, we will explore the relationship between person-centred communication and healthcare providers' self-reported communications skills, level of empathy, mindfulness and emotional intelligence, and develop a rating scale for personcentred communication and care.

\section{METHODS AND DESIGN \\ Study design}

This is an international cross-sectional study with a descriptive and comparative design.

\section{Settings and samples}

cThe study includes three studies: study 1 targets communication in home healthcare in the three participating European countries. In Norway, the additional two studies target communication during CT examinations (study 2) and in private optometric practices (study 3 ). For all three studies, the patient samples comprises older people ( $\geq 65$ years) living at home who utilise these health services. All patients included are able to give informed consent, excluding persons with diagnosed dementia.

Nurses, nurse assistants, radiographers and optometrists with a contract of long-term or permanent employment are eligible to participate in the study to ensure that participants are present and to allow for planning of data collection. A maximum variation sampling strategy to recruit healthcare providers ensures variation in gender, age, time of employment and professional experience.

The data collection utilises three different sources. The communication between older people and care providers is audiorecorded for studies 1 and 2, and video recorded for study 3. Questionnaires yield information about participating care providers, including demographics, selfefficacy of communication skills, aspects of empathy, mindfulness and emotional intelligence (table 1). The local computer-based registration systems of the respective units of healthcare services provide anonymous data on representativeness of participants compared to all patients in the unit, their service needs and healthcare workers (staff composition, age, education).

All observational data is coded with the $\operatorname{RIAS}^{58}$ and the VR-CoDES. ${ }^{57}{ }^{62}$ Study 3 includes additional data on patient-centred communication described in a section in study 3 .

\section{Study 1: Current practice in home healthcare}

Targeted care providers are registered nurses and nurse assistants working in home healthcare. Units of home healthcare services are located in two municipalities in Norway, one municipality in Sweden and several different units in the Netherlands (individual participants, nurses/nurse assistants), which provide around 500 audiorecordings of encounters between older people and home healthcare providers.

\section{Study 2: Person-centred communication during CT examination}

Targeted care providers are radiographers $(n=10)$ performing CT examinations and five of their encounters, each with older outpatients $(n=50)$. 
Table 1 Questionnaires used to measure care providers' self-reported communication skills, empathy, mindfulness and emotional intelligence

\begin{tabular}{|c|c|c|c|}
\hline Concept & Questionnaires & Items and scale & Focus \\
\hline $\begin{array}{l}\text { Communication } \\
\text { self-efficacy }\end{array}$ & $\begin{array}{l}\text { Klar tale til patienterne } 64 \\
\text { (Clear-cut communication with } \\
\text { patients) }\end{array}$ & $\begin{array}{l}21 \text { Items } \\
\text { Numerical } 1-10 \\
5 \text {-point Likert scale }\end{array}$ & $\begin{array}{l}\text { Communication skills in clinical practice } \\
\text { Confidence to succeed in daily work related to } \\
\text { managing emotions, the use of time, } \\
\text { conveying messages and involving patients } \\
\text { Confidence and importance to succeed in } \\
\text { communication with patients }\end{array}$ \\
\hline Empathy & $\begin{array}{l}\text { Jefferson Scale of } \\
\text { Empathy }^{6566}\end{array}$ & $\begin{array}{l}20 \text { items } \\
7 \text {-point Likert scale }\end{array}$ & $\begin{array}{l}\text { Empathy in clinical practice } \\
\text { Understanding the patient's concerns, pain } \\
\text { and suffering and having a desire to help them }\end{array}$ \\
\hline Mindfulness & $\begin{array}{l}\text { Langer 14-item Mindfulness }{ }^{51} \\
\text { Scale }\end{array}$ & $\begin{array}{l}14 \text { items } \\
7 \text {-point Likert scale }\end{array}$ & $\begin{array}{l}\text { Components of sociocognitive mindfulness } \\
\text { Novelty seeking, novelty producing and } \\
\text { engagement } \\
\text { Presence or absences of attention to and } \\
\text { awareness of what is occurring in the present }\end{array}$ \\
\hline $\begin{array}{l}\text { Emotional } \\
\text { intelligence }\end{array}$ & $\begin{array}{l}\text { Trait Emotional Intelligence } \\
\text { Questionnaire-Short Form }\end{array}$ & $\begin{array}{l}30 \text { items } \\
7 \text {-point Likert scale }\end{array}$ & $\begin{array}{l}\text { Fifteen facets of emotional intelligence } \\
\text { How well people understand and manage their } \\
\text { emotions, interpret and relate to the feelings of } \\
\text { others and use this knowledge in relationship }\end{array}$ \\
\hline
\end{tabular}

\section{Study 3: Person-centred communication in optometric} practice

All private optometric practices in Drammen and Hallingdal municipalities receive an invitation to participate in the study. The study sample will consist of practising optometrists $(n=10)$ and five of their encounters, each with older patients $(n=50)$.

The optometric encounters are additionally analysed using Four Habits Coding Scheme (FHCS), ${ }^{63}$ and the older people's reports on optometrists' communication and preference of communication are collected using the Four Habits Patient Questionnaire. ${ }^{63}$

\section{Participant recruitment}

The local regional and county councils of the participating universities (Norway and Sweden) will be used for data gathering in Norway and Sweden. In Norway, two municipalities ( 1 urban and 1 rural district) will participate in order to get a broad sample, representative of the different challenges the healthcare providers face. In Sweden, home healthcare settings in a midsized town area will be approached for data gathering, and recruitment of healthcare providers and elderly persons. In the Netherlands, recruitment of the home health caregivers will be done through home care organisations and individual caregivers, located in different parts of the country. The optometric and the radiographer participants will be in explorative convenience samples recruited in collaboration with the existing partners.

The management at the specific units of healthcare services recruit the healthcare staff. Information about the study and participation is presented by members of the national research teams both written and orally to all healthcare providers at routine staff meetings in each unit. A staff member at the different sites will collect written informed consent.

Participants, older people and care providers can withdraw from the study at any time and have their data deleted.

\section{Study 1: Current practice in home healthcare}

Care providers employed at each site serve as gatekeepers in contact with older people who receive home healthcare. The staff will recruit the patients in accordance with the procedure developed and presented by the research team, which includes three steps: (1) identification of older people who fit the inclusion criteria; (2) delivery of standardised written and oral information about the study to eligible patients during routine visits and (3) collection of written informed consent from patients who agree to participate after a minimum of $24 \mathrm{~h}$ after the given information.

\section{Study 2: Radiographer communication practice during CT examination}

Eligible older people will receive oral and written information about the study from the receptionists of the department on the day of examination. The participating radiographers collect written informed consent from the patients who choose to participate before the CT examination starts.

\section{Study 3: Person-centred communication in optometric practice}

Eligible older people will receive oral and written information about the study from the staff of the participating optometric practice. The optometrists collect written informed consent from the patients before the consultation starts. 
Questionnaires and coding systems

Questionnaires

In addition to demographic data, questionnaires include information about healthcare providers' self-reported communication skills, empathy, mindfulness and emotional intelligence including: 'Clear-cut communication with patients', ${ }^{64}$ Jefferson Empathy Scale, ${ }^{65}{ }^{66}$ Langer 14-item scale ${ }^{51}$ and Trait Emotional Intelligence Questionnaire-Short Form ${ }^{67}$ are shown in table 1.

\section{Coding systems for verbal communication-VR-CoDES C-C (Cues and concerns)}

The coding system has a detailed description of concerns (expression of a negative emotion), and specification of seven different ways of hinting or cueing emotionally important topics. ${ }^{57}$ VR-CoDES C-C has been validated with patients having chronic pain (fibromyalgia), and has been found to have a very high degree of sensitivity and specificity, giving a real picture of patients' major health concerns and also of other life concerns. ${ }^{68}$

\section{VR-CoDES-P (provider responses)}

In the coding system, ${ }^{62}$ care providers' responses to the cues and concerns of older people are coded according to two major conceptual dimensions of the coding system: whether or not the response explicitly refers to the cue/concern and whether or not the provider provides space for further disclosure of the cue or concern. The classification system provides four main classes of provider responses. Each class may be subdivided providing 17 separate categories.

\section{Roter Interaction Analysis System}

RIAS is a coding system extensively used in communication research not only in physician-patient consultations, but also in other professional settings such as nurses, ${ }^{32}$ radiographers, ${ }^{69}$ nurse assistants, ${ }^{70}$ pharmacists $^{71}$ and veterinary practices. ${ }^{72}$ All utterances made by the care provider and the older person during a visit are coded and classified. ${ }^{58}{ }^{73}$ An utterance is defined as the smallest discriminable speech segment to which a coder can assign a classification and that expresses or implies a complete thought. RIAS has 39 exclusive and exhaustive categories: 13 are socioemotional and 26 task focused. Examples of coding categories are open-ended medical or therapeutic questions, close-ended medical or therapeutic questions, reassurance and agreement. Several studies in the participating countries have used the system. ${ }^{74-77}$

\section{Four Habits Coding Scheme}

FHCS is a rating scale, which combines evaluative and descriptive elements of communication behaviour, ${ }^{78}$ and provides an outcome measure for communication skills. $^{79}$ The coding scheme scores 23 items organised into four habits: investing in the beginning, eliciting the patient's perspective, demonstrating empathy and investing at the end of the visit. The score is the sum of the
23 items scored on a five-point scale: from $1=$ not very effective to 5 =highly effective. A study on communication training of physicians in Norway has used The Four Habits programme. ${ }^{63}$

\section{Qualitative analysis}

Qualitative methods, such as content analysis, ${ }^{80}$ will be used on a subset of data to further provide in-depth analyses on good and effective communication patterns and challenging communication situations. The qualitative analyses also intend to discover characteristics of personcentred communication. These analyses will illuminate the older person's expressions and the care provider's expressions in the encounters. The analysis of verbal communication will focus on discourses found in sending and receiving words and cues, and will be directed towards patterns of discourse of power and vulnerability in the communication. Patterns of differences or similarities on dominance or subordination may be compared as well as the other expressions of power and vulnerability found in the analysis. ${ }^{81}$ We will also use gender and intersectional theories. ${ }^{82}$ The analysis will identify and analyse challenging communicative situations with respect to the content of these situations. Furthermore, 10-15 transcribed audiorecordings will be analysed according to principles of conversation analysis (CA). One focus in this analysis will be on expressions of power and vulnerability in the communication. Another focus is the understanding of interaction when using a CA methodology compared with the understanding of interaction using RIAS or VR-CoDES. By this approach, CA can contribute to the development of methodological understanding. ${ }^{83}$

The qualitative analyses will be carried out by four different researchers, all trained and well experienced in qualitative approaches. These analyses will start by the researchers reading through a number of transcribed dialogues, and analysing them together. The results of the analysis will be discussed and compared in order to establish consensus on the coding and analysis process. Thereafter, the researchers will continue to analyse the transcripts independently, and continue to discuss and compare their work on a regular basis. Finally, the results of all analyses will be discussed within the whole research team. The qualitative analyses will adhere to the quality criteria outlined by Lincoln and $\mathrm{Guba}^{84}$ to assure trustworthiness and rigour, that is, credibility, transferability, dependability and confirmability.

\section{Statistical analyses}

Information about the respective healthcare units, including patients and demographics on staff, will describe the sample. Observational data from audiorecordings and video recordings, and the questionnaires will provide data on an individual level. Descriptive statistics are used to describe characteristics of the verbal communication in home healthcare, during CT examinations and in optometric practice in terms of frequency 
and distribution of categories within the two observational methods, RIAS and VR-CoDES, and from the questionnaires.

Variation is expected to be found in care providers' standards and their levels of training, within and across participating countries; this is similar to earlier studies on competence of staff and staffing levels at nursing homes. ${ }^{22} 85$ Differences in communication behaviours between professionals within groups of care providers can be expected on the basis of different levels of education. ${ }^{22}$ Moreover, differences are expected to be found between professionals in different healthcare settings. To examine these aspects more closely, analyses aimed at determining whether differences in staffing standards, educational levels or professional background have significant and distinct effect on communication behaviour are performed. This will be explored statistically using linear mixed models (LMM). LMM will allow comparison of data at different levels and thus, help to investigate whether communication behaviours and/or characteristics differ between groups of care providers, units, settings or countries. LMM will also explore the influence of factors extracted from the questionnaires and the communication expressed as results from RIAS and VR-CoDES. This can identify possible correlations between given individual characteristics of reported communication skills, empathy, mindfulness and emotional intelligence, and communication behaviours. For all statistical analyses, $\mathrm{p}$ value of 0.05 or less are considered statistically significant.

\section{ETHICS AND DISSEMINATION}

Depending on national legislation, approval of either the central ethical committees (eg, nation or university), the national data protection officials or the local ethical committees (eg, units of home healthcare) was obtained.

The sampling of care providers and patients, the storage, flows and access of the data are in accordance with legislation and safety routines in each country and the collaborating research institutions, respectively, to safeguard the security, privacy and confidentiality.

Study findings will be disseminated widely through peer-reviewed publications and conference presentations. The research findings will add knowledge to improve services provided to this vulnerable group of patients. Additionally, the findings will underpin a training programme for healthcare students and care providers focusing on communication with older people.

\section{DISCUSSION AND CONCLUSION}

We expect that comparing communication and interaction between older people and healthcare providers in different settings and countries will provide valuable insight into aspects of person-centred communication. All three countries have a healthcare system of high quality; they have different organisational models of healthcare services and have to meet the challenges relating to an ageing population and limited healthcare resources while aiming for providing person-centred healthcare. This cross-national design allows us to explore patterns and attributes of communication practice within and between participating countries and enables us to make suggestions for best practice that can serve as examples for future healthcare and healthcare education.

\section{Theoretical contribution}

Person-centred healthcare and person-centred communication are complex issues. This complicates the definitions of the concepts. We believe that this project will make a significant contribution to research and theory of person-centred communication between care providers and older people by providing descriptions of communication behaviour in practice, by identifying important traits relating to care providers and by examining what factors facilitate or hinder the fulfilment of person-centred communication. Findings will highlight aspects important to increasing the participation and enhancing the self-determination of older persons as well as decreasing unnecessary distress. All of this may, in turn, contribute towards improving the overall health and well-being of older persons.

The providers' self-reported rating of communication skills, empathy, mindfulness and emotional intelligence will give a broad description of traits known to impact on communication in healthcare settings. The combination of data from the observational analysis of the visits, rating scales and the questionnaires can give indications of the traits of the healthcare provider that are important to facilitating person-centred communication.

\section{Methodological contribution}

There are many ways to analyse communications in healthcare. We have chosen to use two instruments, VR-CoDES and RIAS, and the FHCS for optometric practice. RIAS is a commonly used instrument for describing provider-patient communication and has been used in numerous studies in various healthcare contexts. ${ }^{58}$ RIAS has previously been used to identify person-centred talk between patients and physicians; this is identified as the doctor's ability to include conversation pertaining to psychosocial aspects and lifestyle, engaging with the patient in partnership-building utterances, welcoming patients' questions and being attentive to patients' information about psychosocial aspects and lifestyle. $^{39}$ The VR-CoDES scheme identifies patients' utterances that contain concerns and the providers' responses to the patients' concerns. ${ }^{57}$ Exploring how these emotional moments unfold and are met in practice contributes towards describing person-centred communication as shown by Eide and colleagues, who explored fibromyalgia patients' emotional utterances and nurses' responses in an outpatient clinic context. ${ }^{26}$ Research shows that the physician's ability to communicate effectively with older patients impacts on patients' 
emotional outcomes and decreases hospitalisation. ${ }^{86}$ The ability of the healthcare provider to respond to older peoples' emotional concerns may be important to ensure both health and well-being, but also to enable older people to cope with daily tasks and live at home as long as possible. Exploring different dimensions of the communication between the older person and the care provider in home healthcare, during CT examinations and optometric examinations can shed light on what facilitates or hinders person-centred communication in different health contexts.

\section{Implications for practice}

Further analysis of the real-life visits using qualitative methods can provide a deeper understanding of the mechanisms in play in the health provider-patient relationship. Hence, the combination of observational and qualitative methods might provide a broad and rich picture of how communication between healthcare providers and older people naturally occurs. The quality and level of person-centred communication in these visits is essential for the well-being and participation of the older people, which is vital since attitudes towards care for the elderly need to be improved. ${ }^{86}$

The study includes samples from different countries and enables broad descriptions and comparisons, and provides a solid base for further studies. The present study will also contribute to develop the use of RIAS and VR-CoDES in professional groups other than the patient-physician encounter, providing valuable methodological input. Finally, the descriptive data from the participating countries will lay the ground for an evidence-based education platform, targeting healthcare staff working with older people and healthcare students on different levels.

\section{Author affiliations}

${ }^{1}$ Faculty of Health Sciences, Buskerud and Vestfold University College, Drammen, Norway

${ }^{2}$ School of Health, Care and Social Welfare, Mälardalen University, Västerås, Sweden

${ }^{3}$ School of Health and Education, University of Skövde, Skövde, Sweden

${ }^{4}$ Department of Public Health and Caring Sciences, Uppsala University, Uppsala, Sweden

${ }^{5}$ NIVEL (Netherlands Institute for Health Services Research), Utrecht, The Netherlands

${ }^{6}$ Department of Primary and Community Care, Radboud University Medical Center, Nijmegen, The Netherlands

Acknowledgements In planning and executing the project, we have received helpful input and support from participating municipalities and healthcare units.

Contributors HE conceived the idea of the study. LH, AJS, IKH, VS, SVD and $\mathrm{HE}$ initiated the study design and implementation. All authors read and approved the final manuscript.

Funding This work was supported by the Norwegian Research Council, grant no. 226537 (PraksisVEL), as well as the coauthors' own institutions. All work relating to the project is independent of the funders.

Competing interests None.

Ethics approval Norway: Norwegian Social Science Data Services (NSD) No. 36017 and Regional Committees for Medical and Health Research Ethics
(REK), No. 2013/1626/REK sør-øst B. Sweden: Regional Ethics Committee in Uppsala, Dnr 2014/018; The Netherlands: Commissie Mensgebonden Onderzoek, Radboud University Medical Centre; No. 2014/045.

Provenance and peer review Not commissioned; peer reviewed for ethical and funding approval prior to submission.

Open Access This is an Open Access article distributed in accordance with the Creative Commons Attribution Non Commercial (CC BY-NC 4.0) license, which permits others to distribute, remix, adapt, build upon this work noncommercially, and license their derivative works on different terms, provided the original work is properly cited and the use is non-commercial. See: http:// creativecommons.org/licenses/by-nc/4.0/

\section{REFERENCES}

1. van Vliet LM, Epstein AS. Current State of the art and science of patient-clinician communication in progressive disease: patients' need to know and need to feel known. J Clin Oncol 2014;32:3474-8.

2. Greene MG, Adelman RD, Friedmann E, et al. Older patient satisfaction with communication during an initial medical encounter. Soc Sci Med 1994;38:1279-88.

3. Rogers CR. The necessary and sufficient conditions of therapeutic personality change. J Consult Psychol 1957;21:95-103.

4. Gorawara-Bhat R, Dethmers DL, Cook MA. Physician eye contact and elder patient perceptions of understanding and adherence. Patient Educ Couns 2013;92:375-80.

5. Svanström R, Johansson Sundler A, Berglund M, et al. Suffering caused by care-elderly patients' experiences in community care. Int J Qual Stud Health Wellbeing 2013;8:20603.

6. HOD. Folkehelsemeldingen. God helse-fellesansvar [Public Health Report-Meld. St. 34 (2012-2013) Report to the Storting (White Paper)]. Oslo: Det kongelige Helse-Og Omsorgsdepartementet, 2013.

7. HOD. Innovasjon i omsorg [Innovation in the Care Services]. Oslo: Det kongelige Helse-Og Omsorgsdepartementet, 2011.

8. HOD. Samhandlingsreformen. Rett behandling-på rett sted-til rett tid [Report No. 47 to the Storting (2008-2009) The Coordination Reform-Proper treatment-at the right place and right time]. Oslo: Det kongelige Helse- Og Omsorgsdepartementet, 2009.

9. Ministry of Health Welfare and Sport. Strategische kennisagenda 2020 VWS [Strategic knowlegde agenda]. The Hague, 2012.

10. Socialstyrelsen. Bostad i särskilt boende är den enskildes hem [The National Board of Health and Welfare, Housing in special ackommodation is the person's home], 2011.

11. Huang LH, Lin YC. The health status and needs of community elderly living alone. J Nurs Res 2002;10:227-36.

12. Heikkinen E. What are the main risk factors for disability in old age and how can disability be prevented? Copenhagen: WHO Regional Office for Europe, 2003.

13. Holmström I, Röing M. The relation between patient-centeredness and patient empowerment: a discussion on concepts. Patient Educ Couns 2010;79:167-72.

14. Little P. Preferences of patients for patient centred approach to consultation in primary care: observational study. BMJ 2001;24(322 (7284)):468-72.

15. Michie S, Miles J, Weinman J. Patient-centredness in chronic illness: what is it and does it matter? Patient Educ Couns 2003;51:197-206.

16. Ekman I, Wolf A, Olsson L-E, et al. Effects of person-centred care in patients with chronic heart failure: the PCC-HF study. Eur Heart $J$ 2012;33:1112-21.

17. Stange KC, Nutting PA, Miller WL, et al. Defining and measuring the patient-centered medical home. J Gen Intern Med 2010;25:601-12.

18. Day $\mathrm{H}$, Eckstrom $\mathrm{E}$, Lee $\mathrm{S}$, et al. Optimizing health for complex adults in primary care: current challenges and a way forward. J Gen Intern Med 2014;29:911-4.

19. Heine C, Browning CJ. Communication and psychosocial consequences of sensory loss in older adults: overview and rehabilitation directions. Disabil Rehabil 2002;24:763-73.

20. Lawrence M, Kinn S. Defining and measuring patient-centred care: an example from a mixed-methods systematic review of the stroke literature. Health Expect 2012;15:295-326.

21. Davies S, Laker S, Ellis L. Promoting autonomy and independence for older people within nursing practice: a literature review. $J$ Adv Nurs 1997;26:408-17.

22. Caris-Verhallen WM, de Gruijter IM, Kerkstra A, et al. Factors related to nurse communication with elderly people. J Adv Nurs 1999;30:1106-17. 
23. Vivian BG, Wilcox JR. Compliance communication in home health care: a mutually reciprocal process. Qual Health Res 2000;10:103-16.

24. Oresland S, Lutzén K, Norberg A, et al. Nurses as 'guests'-a study of a concept in light of Jacques Derrida's philosophy of hospitality. Nurs Philos 2013;14:117-26.

25. Oresland S, Maatta S, Norberg A, et al. Nurses as guests or professionals in home health care. Nurs Ethics 2008;15:371-83.

26. Eide H, Sibbern T, Egeland T, et al. Fibromyalgia patients' communication of cues and concerns: interaction analysis of pain clinic consultations. Clin J Pain 2011;27:602-10.

27. Adams R, Price K, Tucker G, et al. The doctor and the patient-how is a clinical encounter perceived? Patient Educ Couns 2012;86:127-33.

28. Booth $\mathrm{L}$. The radiographer-patient relationship: enhancing understanding using a transactional analysis approach. Radiography 2008:14:323-31.

29. Munn Z, Jordan Z. The patient experience of high technology medical imaging: a systematic review of the qualitative evidence. Radiography 2011;17:323-31.

30. Caris-Verhallen WM, Kerkstra A, Bensing JM. The role of communication in nursing care for elderly people: a review of the literature. J Adv Nurs 1997;25:915-33.

31. Jansen J, van Weert J, van Dulmen S, et al. Patient education about treatment in cancer care: an overview of the literature on older patients' needs. Cancer Nurs 2007;30:251-60.

32. Caris-Verhallen WM, Kerkstra A, van der Heijden PGM, et al. Nurse-elderly patient communication in home care and institutional care: an explorative study. Int J Nurs Stud 1998;35:95-108.

33. Mathers SA, Chesson RA, McKenzie GA. The information needs of people attending for computed tomography (CT): what are they and how can they be met?. Patient Educ Couns 2009;77:272-8.

34. Basu PA, Ruiz-Wibbelsmann JA, Spielman SB, et al. Creating a patient-centered imaging service: determining what patients want. Am J Roentgenol 2011;196:605-10.

35. Murphy F. Understanding the humanistic interaction with medical imaging technology. Radiography 2001;7:193-201.

36. Sundling V, Gulbrandsen P, Bragadottir R, et al. Optometric practice in Norway: a cross-sectional nationwide study. Acta Ophthalmol Scand 2007:85:671-6.

37. Holmberg $\mathrm{O}$, Malone $\mathrm{J}$, Rehani $\mathrm{M}$, et al. Current issues and actions in radiation protection of patients. Eur $J$ Radiol 2010;76:15-19.

38. Pines JM, Mullins PM, Cooper JK, et al. National trends in emergency department use, care patterns, and quality of care of older adults in the United States. J Am Geriatr Soc 2013;61:12-7.

39. Mead N, Bower P. Patient-centredness: a conceptual framework and review of the empirical literature. Soc Sci Med 2000;51:1087-110.

40. McCormack B, McCance T. Person-centred nursing: theory and practice. Chichester, West Sussex: Wiley-Blackwell, 2010.

41. Fifth Geneva Conference on Person-centered Medicine and Board of the International College of Person-centered Medicine. In Geneva: Geneva Declaration on Person-centered Care for Chronic Diseases, 2012.

42. Entwistle VA, Watt IS. Treating patients as persons: a capabilities approach to support delivery of person-centered care. Am J Bioeth 2013;13:29-39.

43. Epstein RM, Street RL. The values and value of patient-centered care. Ann Fam Med 2011:9:100-3.

44. Rogers CR. A way of being. New York: Houghton Mifflin Company, 1980.

45. Scholl I, Zill JM, Härter M, et al. An integrative model of patient-centeredness-a systematic review and concept analysis. PLOS ONE 2014:9:e107828.

46. Constand M, MacDermid JC, Dal Bello-Haas V, et al. Scoping review of patient-centered care approaches in healthcare. BMC Health Serv Res 2014;14:271.

47. Reynolds WJ, Scott B. Empathy: a crucial component of the helping relationship. J Psychiatr Ment Health Nurs 1999;6:363-70.

48. Street R Jr, Makoul G, Arora NK, et al. How does communication heal? Pathways linking clinician-patient communication to health outcomes. Patient Educ Couns 2009;74:295-301.

49. Farrell C, Molassiotis A, Beaver K, et al. Exploring the scope of oncology specialist nurses' practice in the UK. Eur J Oncol Nurs 2011;15:160-6.

50. Heaven CM, Maguire P. Disclosure of concerns by hospice patients and their identification by nurses. Palliat Med 1996;23:280-6.

51. Pirson M, Langer E, Bodner T. The Development and Validation of the Langer Mindfulness Scale-Enabling a Socio-Cognitive Perspective of Mindfulness in Organizational Contexts. Fordham University Schools of Business Research Paper 2012.
52. Brown KW, Ryan RM, Creswell JD. Mindfulness: theoretical foundations and evidence for its salutary effects. Psychol Inquiry 2007;18:211-37.

53. Krasner MS. Association of an educational program in mindful communication with burnout, empathy, and attitudes among primary care physicians. JAMA 2009;302:1284-93.

54. Beach MC, Roter D, Korthuis PT, et al. A multicenter study of physician mindfulness and health care quality. Ann Fam Med 2013;11:421-8.

55. Cherry MG, Fletcher I, O'sullivan $\mathrm{H}$, et al. What impact do structured educational sessions to increase emotional intelligence have on medical students? BEME Guide No. 17. Med Teach 2012;34:11-19.

56. McQueen $\mathrm{ACH}$. Emotional intelligence in nursing work. J Adv Nurs 2004;47:101-8

57. Zimmermann C, Del Piccolo L, Bensing J, et al. Coding patient emotional cues and concerns in medical consultations: the Verona Coding Definitions of Emotional Sequences (VR-CoDES). Patient Educ Couns 2011;82:141-8.

58. Roter D, Larson S. The Roter Interaction Analysis System (RIAS): utility and flexibility for analysis of medical interactions. Patient Educ Couns 2002;46:243-51.

59. Edvardsson D, Nilsson A, Fetherstonhaugh D, et al. The person-centred care of older people with cognitive impairment in acute care scale (POPAC). J Nurs Manag 2013;21:79-86.

60. Edvardsson D, Innes A. Measuring person-centered care: a critical comparative review of published tools. Gerontologist 2010;50:834-46.

61. Dow B, Fearn M, Haralambous B, et al. Development and initial testing of the person-centred health care for older adults survey. Int Psychogeriatr 2013;25:1065-76.

62. Del Piccolo L, de Haes H, Heaven C, et al. Development of the Verona Coding Definitions of Emotional Sequences to code health providers' responses (VR-CoDES-P) to patient cues and concerns. Patient Educ Couns 2011;82:149-55.

63. Fossli Jensen B, Gulbrandsen P, Dahl FA, et al. Effectiveness of a short course in clinical communication skills for hospital doctors: results of a crossover randomized controlled trial (ISRCTN22153332). Patient Educ Couns 2011;84:163-9.

64. Klar tale med patienterne-Spørgeskema 1 til klinisk personale [Clear-cut communication with patients]: Sygehus Lillebælt, Enhed for Sundhedstjenesteforskning, 2012.

65. Hojat M, Gonnella JS, Nasca TJ, et al. The Jefferson Scale of Physician Empathy: further psychometric data and differences by gender and specialty at item level. Acad Med 2002;77(10 Suppl): S58-60.

66. Hojat M, Mangione S, Kane GC, et al. Relationships between scores of the Jefferson Scale of Physician Empathy (JSPE) and the Interpersonal Reactivity Index (IRI). Med Teach 2005;27:625-8.

67. Cooper A, Petrides KV. A psychometric analysis of the Trait Emotional Intelligence Questionnaire-Short Form (TEIQue-SF) using item response theory. J Pers Assess 2010;92:449-57.

68. Eide $\mathrm{H}$, Eide $\mathrm{T}$, Rustøen $\mathrm{T}$, et al. Patient validation of cues and concerns identified according to Verona Coding Definitions of Emotional Sequences (VR-CoDES): a video- and interview-based approach. Patient Educ Couns 2011;82:156-62.

69. Bjorkman B, Golsäter M, Simeonson RJ, et al. Will it hurt? Verbal interaction between child and radiographer during radiographic examination. J Pediatr Nurs 2013;28:e10-18.

70. van Weert JC, van Dulmen AM, Spreeuwenberg PMM, et al. Effects of snoezelen, integrated in $24 \mathrm{~h}$ dementia care, on nurse-patient communication during morning care. Patient Educ Couns 2005;58:312-26.

71. Cavaco A, Roter D. Pharmaceutical consultations in community pharmacies: utility of the Roter Interaction Analysis System to study pharmacist-patient communication. Int J Pharm Pract 2010;18:141-8.

72. McArthur ML, Fitzgerald JR. Companion animal veterinarians' use of clinical communication skills. Aust Vet J 2013;91:374-80.

73. Roter DL. Patient participation in the patient-provider interaction: the effects of patient question asking on the quality of interaction, satisfaction and compliance. Health Educ Monogr 1977;5:281-315.

74. Eide H, Frankel R, Haaversen ACB, et al. Listening for feelings: identifying and coding empathic and potential empathic opportunities in medical dialogues. Patient Educ Couns 2004;54:291-7.

75. Eide H, Quera V, Graugaard P, et al. Physician-patient dialogue surrounding patients' expression of concern: applying sequence analysis to RIAS. Soc Sci Med 2004;59:145-55

76. van Dulmen S, Tromp F, Grosfeld F, et al. The impact of assessing simulated bad news consultations on medical students' stress response and communication performance. Psychoneuroendocrinology 2007;32:943-50. 
77. Ernesater A, Winblad U, Engstrom M, et al. Malpractice claims regarding calls to Swedish telephone advice nursing: what went wrong and why? J Telemed Telecare 2012;18:379-83.

78. Krupat E, Frankel R, Stein T, et al. The Four Habits Coding Scheme: validation of an instrument to assess clinicians' communication behavior. Patient Educ Couns 2006;62:38-45.

79. Fossli Jensen B, Gulbrandsen P, Benth JS, et al. Interrater reliability for the Four Habits Coding Scheme as part of a randomized controlled trial. Patient Educ Couns 2010;80:405-9.

80. Hsieh HF, Shannon SE. Three approaches to qualitative content analysis. Qual Health Res 2005;15:1277-88.

81. Foucault M. Power/knowledge. Selected interviews and other writings 1972-1977. Brighton: Gordon, 1980.
82. Höglund AT, Holmström I. 'It's easier to talk to a woman' Aspects of gender in Swedish telenursing. J Clin Nurs 2008;17:2979-86.

83. Ford CE. Clarity in applied and interdisciplinary conversation analysis. Discourse Studies 2012;14:507-13.

84. Lincoln YS, Guba EG. Naturalistic inquiry. Newbury Park, CA: Sage Publications, 1985

85. Harrington C, Choiniere J, Goldmann M, et al. Nursing home staffing standards and staffing levels in six countries. J Nurs Scholarsh 2012;44:88-98.

86. Stewart M, Meredith L, Brown JB, et al. The influence of older patient-physician communication on health and health-related outcomes. Clin Geriatr Med 2000;16:25-36, vii-viii. 